\title{
AVALIAÇÃO DIGITAL NO ENSINO SUPERIOR EM PORTUGAL: primeiros resultados ${ }^{1}$
}

\author{
Maria João Gomes* \\ Lúcia Amante ${ }^{* *}$ \\ Isolina Oliveira $^{* * *}$
}

\section{Resumo}

A avaliação de competências requer uma abordagem que integre conhecimento, habilidades e atitudes, implicando o recurso a diversas estratégias de avaliação. Neste contexto, temos assistido à emergência de um novo conceito, designado por vários autores como cultura da avaliação. Além disso, os ambientes virtuais de aprendizagem do ensino superior têm também promovido a utilização de novas estratégias de avaliação eletrónica. Portanto, torna-se importante repensar o conceito de qualidade da avaliação nos contextos de educação superior online e, particularmente, como desenvolver na atualidade novos cenários de aprendizagem. Neste texto apresentamos um novo quadro teórico para a avaliação digital na educação superior, ancorado em quatro dimensões - autenticidade, consistência, transparência e viabilidade - cada uma delas integrando um conjunto de parâmetros, que visa promover a qualidade das estratégias de avaliação em uso. Com base neste quadro teórico discutem-se ainda os primeiros dados do trabalho de campo realizado, considerando os resultados de um questionário sobre a utilização das tecnologias e serviços digitais para a avaliação (digital), aplicado a professores de todas as universidades públicas portuguesas.

Palavras-chave: Avaliação digital. E-learning. Ensino superior. Competências.

\section{DIGITAL IN HIGHER EDUCATION ASSESSMENT IN PORTUGAL: first results}

\begin{abstract}
The assessment of competences requires an approach where knowledge, abilities and attitudes are integrated, naturally implying the resource to a variety of assessment strategies. Within this context we have seen the emergence of what has been called by several authors the Assessment Culture. Furthermore, higher education elearning environments have also promoted the use of new e-assessment strategies. Therefore, it is important to reconsider the concept of quality assessment in higher education online contexts, and particularly how to develop it in the present learning landscapes. In this paper, we present a new theoretical framework for e-assessment in higher education supported by four dimensions - authenticity, consistency, transparency and practicability each composed by a set of parameters, aimed at promoting the quality of the assessment strategies being used. Based in this framework we also discussed the first outcomes of our field research through a questionnaire applied to all Portuguese universities.
\end{abstract}

Keywords: E-assessment. E-learning. Higher education. Competences.

1 Projeto @ssess.he. Projeto Financiado pela Fundação para a Ciência e Tecnologia (PTDC/CPECED/104373/2008). Ministério da Educação e Ciência- Portugal. Para além das autoras, integram o projeto @ssess.he Alda Pereira, Maria de Jesus Relvas, Ana Nobre, Maria do Carmo Teixeira Pinto, Teresa Cardoso e Luís Nunes da Silva.

* Doutora em Educação. Professora da Universidade do Minho - Portugal. E-mail: mjgomes@ie.uminho.pt ** Doutora em Ciências da Educação e Professora da Universidade Aberta de Portugal. E-mail: lamante@uab.pt

*** Doutora em Ciências da Educação pela Universidade de Lisboa - Portugal. Professora da Universidade Aberta de Portugal. E-mail: isolina@uab.pt 


\section{Introdução}

O novo cenário educativo resultante da construção do Espaço Europeu da Educação Superior (EEES) permite a mobilidade dos estudantes e a compatibilidade dos graus académicos/títulos universitários. Entre outros, este cenário tem como objetivos a capacitação de profissionais e cidadãos que, para além da apropriação de conhecimento técnico-científico, devem desenvolver um conjunto de competências que lhes permitam enfrentar com sucesso situações complexas no exercício das suas profissões. Neste contexto, privilegiam-se competências gerais que todos devem desenvolver numa perspetiva de aprendizagem ao longo da vida, e a sua respetiva avaliação. Especificamente, advoga-se o desenvolvimento de competências relacionadas com o trabalho em equipa, a capacidade de planificar, as capacidades de comunicação, de pesquisa e processamento de informação, de análise e síntese e de usar ferramentas tecnológicas. Numa perspetiva holística e abrangente, o projeto destaca três categorias de competências-chave (OCDE, 2002): agir autonomamente, relacionada com a autonomia e identidade, utilizar ferramentas físicas e socioculturais interativamente e funcionar em grupos socialmente heterogéneos.

As titulações (universitárias) oferecidas no espaço europeu passaram a ser definidas em função das competências gerais e das competências específicas, de acordo com o âmbito académico e profissional.

Esta nova forma de perspetivar a atribuição de um grau académico traz profundas alterações no modo de planear os cursos oferecidos pelas universidades. A ênfase é colocada no estudante e na sua aprendizagem, nas competências a desenvolver e não só no que o professor deve ensinar. Este deslocamento do foco exige a mudança nas metodologias a utilizar, mas também nas estratégias de avaliação a implementar por forma a avaliar as competências desenvolvidas pelos estudantes (AMANTE, 2011). BAARTMAN, BASTIAENS, KIRCHNE e VLEUTEN (2007) sublinham que se os "países europeus querem reformar os seus currículos, a avaliação tem de desempenhar um papel principal no seu processo de reforma e as estratégias de avaliação a implementar têm que se centrar na avaliação integrada de conhecimentos, capacidades, atitudes e valores” (p.115). Neste contexto, os autores (BAARTMAN, BASTIAENS, KIRCHNE \& VLEUTEN, 2007) propõem um Programa de Avaliação de Competências (PAC) que consiste numa combinação de diferentes formas de avaliação, implicando a definição de critérios necessários à análise da sua qualidade.

Reconhece-se que o uso de um único formato de avaliação é insuficiente para fazer a 
avaliação da competência de um dado indivíduo. Torna-se, assim, necessário desenvolver PACs que contemplem novas formas de avaliação, substituindo a "cultura do teste” pela “cultura de avaliação” (BIRENBAUM, 1996; DIERICK \& DOCHY, 2001). A “cultura da avaliação” enraíza-se num olhar crítico relativamente à utilização dos testes como única forma válida de avaliação da aprendizagem e ao apoio excessivo nestes para o planeamento do ensino, e focaliza-se no recurso a múltiplas formas, momentos, intervenientes e processos de avaliação.

Este cenário educativo é marcado pelo desenvolvimento crescente das novas tecnologias, exigindo das pessoas, empresas e universidades outras formas de comunicar, de obter informação e de relações (BLANCO, 2009). Consequentemente, há que gerar estratégias, ferramentas tecnológicas, bem como promover o desenvolvimento de capacidades que possibilitem a adaptação a essas mudanças.

A utilização crescente do elearning e a emergência de perspetivas construtivistas acompanhadas de modelos de aprendizagem distribuída e em rede promovem um papel mais ativo do estudante no seio das comunidades de aprendizagem (PEREIRA, OLIVEIRA \& TINOCA, 2010). Este facto tem levado ao aparecimento de estratégias alternativas de avaliação, de natureza digital (AMANTE, 2011), nomeadamente, a avaliação das tarefas realizadas em grupo e correspondente avaliação entre pares, e a diferentes formas de autoavaliação e reflexão, por parte do estudante, por exemplo, com recurso a e-portefólios. Há, pois, que repensar as estratégias de avaliação nestes ambientes virtuais.

É neste quadro que se desenvolve o projeto Elearning and Assessment in Higher Education - @ssess.he, no qual se insere o estudo a que faremos referência.

\section{contexto do projeto @ssess.he}

A emergência do elearning como modalidade de ensino e de aprendizagem, quer ao nível das instituições de ensino a distância, quer no seio de instituições de ensino superior tradicionalmente presenciais, é atualmente uma realidade inquestionável. Neste contexto, a diversidade de cenários pedagógicos associados ao elearning é múltipla, incluindo a oferta de formação totalmente online, diversas formas híbridas (online+presencial) de formação, configurando cenários de blended learning, podendo ainda considerar-se cenários presenciais enriquecidos com recurso a múltiplos serviços e atividades suportadas em tecnologias digitais.

Apesar da ausência de consenso relativamente aos modelos que podem enformar as formas de elearning, abarcando perspetivas e conceções muito diversas, a crescente integração 
de tecnologias digitais na educação tem permitido novos contextos e cenários em termos das abordagens pedagógicas (GOMES, 2005a 2005b).

Estas abordagens vêm reforçando a centralidade do estudante no processo de aprendizagem, reforçando perspetivas socio-construtivistas e conectivistas, permeadas por modelos de aprendizagem distribuída e em rede, valorizando o desenvolvimento de comunidades de aprendizagem nos ambientes virtuais.

Este processo de progressiva incorporação de práticas de elearning nos contextos de ensino presencial implica forçosamente alterações nos processos, estratégias e atividades de ensino e de aprendizagem e concomitantemente também nos processos de avaliação das próprias aprendizagens. É neste contexto que se enquadra o projeto Elearning e Avaliação no Ensino Superior - @sses.he, o qual visa, em termos globais, identificar e propor estratégias de avaliação diversificadas, adequadas e congruentes com a crescente integração de ambientes digitais de aprendizagem no ensino superior, tendo presente uma perspetiva holística de avaliação de competências.

\section{Os objetivos do projecto @ssess.he}

Tendo subjacente o objetivo geral que se enunciou no ponto anterior, o projeto Elearning e Avaliação no Ensino Superior - @ssess.he estrutura-se em torno de um conjunto de objetivos mais específicos que orientam as diferentes fases e atividades do projeto. Assim, são objetivos do projeto:

(i) Conceber um referencial enquadrador do pensamento referente às caraterísticas do processo e das atividades de avaliação que se apresente coerente e adequado a contextos de aprendizagem, baseados em abordagens socio-construtivistas e conectivistas, e adequado a um contexto de avaliação de competências.

(ii) Identificar práticas e perspetivas dos professores das instituições de ensino público portuguesas, no que concerne à avaliação com recurso a tecnologias digitais.

(iii) Identificar as experiências e perspetivas dos alunos das instituições de ensino público portuguesas relativamente a práticas de avaliação de aprendizagens com recurso a tecnologias digitais.

(iv) Propor modelos e estratégias de avaliação coerentes com o referencial proposto, com recurso a tecnologias digitais e tendo subjacente as especificidades de uma avaliação por competências. 


\section{As fases do projeto e respetivas metodologias de investigação}

Tendo presentes os objetivos específicos que enformam o projeto, num primeiro momento problematizaram-se e confrontaram-se perspetivas no domínio da avaliação das aprendizagens, com foco na centralidade dos estudantes e na perspetiva de uma avaliação por competências, como aflorado na introdução deste texto. Deste processo resultou a elaboração de um referencial enquadrador das práticas de avaliação, o qual se apresenta de forma sucinta na secção seguinte deste texto.

Numa segunda fase, cujos dados preliminares se apresentarão neste texto, procedeu-se a um inquérito por questionário junto de professores de instituições portuguesas de ensino superior público, tendo em vista identificar práticas e perspetivas no que concerne à avaliação com recurso a tecnologias digitais.

Numa terceira fase, em curso, será realizado um inquérito por questionário junto dos alunos de modo a identificar também as suas experiências e perceções relativamente à avaliação no ensino superior com recurso às tecnologias digitais.

Os inquéritos por questionário aos professores e alunos serão elementos importantes na identificação de situações específicas de avaliação com suporte nas tecnologias digitais que, pelas suas caraterísticas, se configurem como particularmente relevantes, tendo em vista a sua análise aprofundada, com o objetivo de estudar os modelos respetivos, a sua implementação e operacionalização, as suas potencialidades, eventuais constrangimentos e seus resultados.

Finalmente, procurar-se-á elucidar processos e práticas de avaliação que se configurem como congruentes com os princípios por nós enunciados no referencial teórico proposto, à luz dos princípios de avaliação por competências com ênfase nos contextos digitais de aprendizagem.

\section{O referencial de avaliação adoptado}

Enquadrado nas reflexões produzidas, elaboramos um referencial enquadrador da atividade de avaliação, numa perspetiva holística de avaliação de competências, que se organiza em torno de quatro dimensões: (i) autenticidade, (ii) consistência, (iii) transparência e (iv) praticabilidade, constituída cada uma delas por diversos parâmetros que as operacionalizam. Este referencial é extensivamente discutido e apresentado em Gomes (2005b). 
A “autenticidade” é reconhecida como fundamental para a avaliação baseada em competências que se pretendem próximas do mundo real/profissional. A "consistência” promove o alinhamento entre avaliação-instrução-competências, e a sua relevância resulta da necessidade de recorrer a uma variedade de formas de avaliação não estandardizadas. A “transparência” promove o envolvimento dos aprendentes, mediante a disponibilização, à partida, de metas e critérios de desempenho e de avaliação, bem como o reconhecimento dos efeitos positivos que a avaliação deve ter na aprendizagem. Por último, mas não menos importante, a "praticabilidade”, que é frequentemente negligenciada, pode influenciar de modo determinante a escolha da estratégia de avaliação a usar.

Na fig. 1, representa-se esquematicamente o referencial de avaliação proposto, identificando cada uma das quatro dimensões e respetivos parâmetros constituintes.

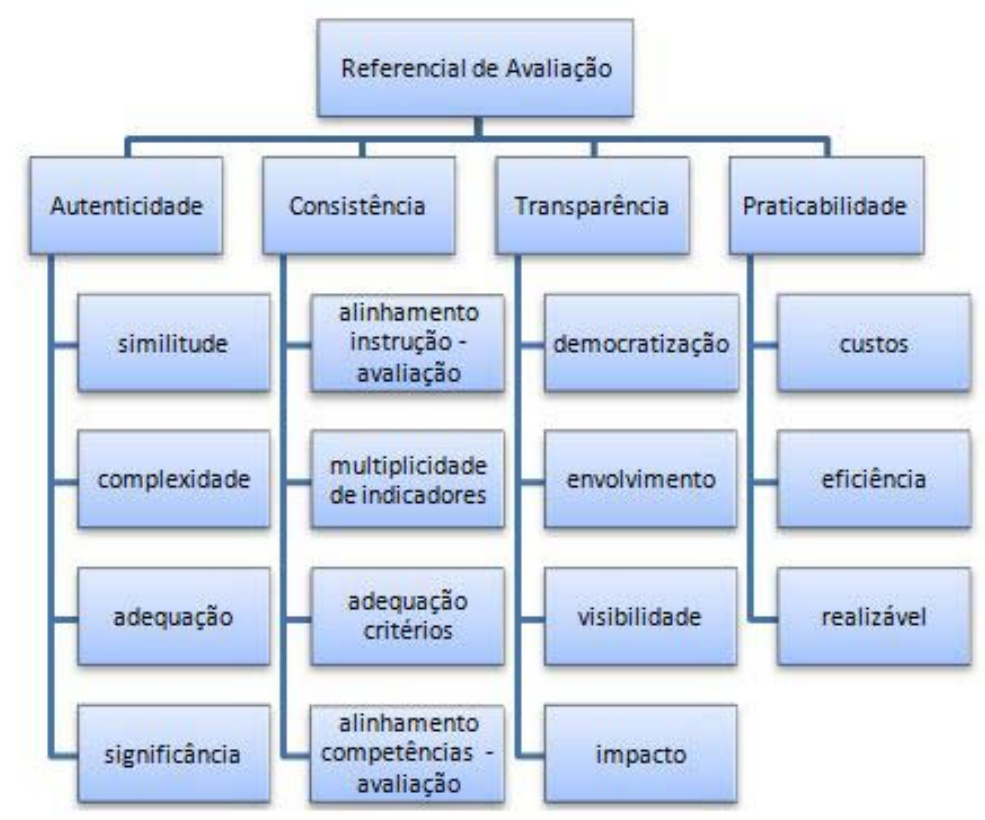

FIG. 1 - Referencial de avaliação

\section{Práticas de avaliação digital no ensino superior}

O questionário aplicado aos professores possui um caráter simultaneamente exploratório e descritivo do que são as práticas e perceções dos professores do ensino superior português relativamente às questões de avaliação, particularmente com recurso a tecnologias digitais. Foi concebido especificamente para este estudo, previamente testado junto de um conjunto de professores do ensino superior e validado junto de especialistas em ensino em contextos de e-learning. 
O questionário foi organizado em torno das seguintes dimensões: (i) identificação biográfica e profissional dos professores, (ii) identificação da modalidade de ensino, ciclo de estudos e curso em que é realizada a avaliação digital; (iii) tomada de decisões sobre o processo de avaliação; (iv) natureza das atividades de avaliação com recurso às tecnologias; (v) tipo de tecnologias utilizadas; (vi) tipo e frequência com que são avaliados um conjunto de competências e (vii) fatores condicionantes do recurso às tecnologias digitais no processo de avaliação. No final do questionário era dada a indicação de que a equipa de investigação pretendia levar a cabo um conjunto de estudos de caso sobre a temática da avaliação com recurso a tecnologias digitais, sendo solicitado aos respondentes que se disponibilizassem para tal, que indicassem um e-mail para contacto posterior.

Em seguida, a apresentação dos principais dados recolhidos através do questionário.

\section{Processo de constituição da amostra}

Assumimos como ponto de partida para o processo de recolha de dados todas as Universidades e Institutos Politécnicos Públicos de Portugal, que passaremos a designar por Instituições de Ensino Superior Público (IESP), excluindo as instituições de Ensino Superior Público Militar e Policial e considerando os cursos dos três ciclos de Bolonha ${ }^{2}$ que no ano letivo de 2010/2011 se encontravam em funcionamento. Na impossibilidade de abarcar todos os cursos em vigor, definimos um conjunto de critérios para identificar os cursos relativamente aos quais iriamos recolher informação.

Como referencial orientador recorremos à Portaria n.0 256/2005 de 16 de março de 2005, do Ministério das Atividades Económicas e do Trabalho, a qual instituiu a Classificação Nacional das Áreas de Educação e Formação (CNAEF), organizada em articulação com a Classificação Internacional Tipo de Educação (CITE) da UNESCO e com as subclassificações da CITE, elaboradas sob supervisão do Gabinete de Estatísticas das Comunidades Europeias (EUROSTAT) e do Centro Europeu para o Desenvolvimento da Formação Profissional (CEDEFOP). Para além de facilitar o processo comparativo a nível europeu, o recurso à CNAEF justifica-se por ser a classificação seguida pela Agência de Avaliação e Acreditação do Ensino Superior (A3ES) em Portugal.

Partindo então da análise da CNAEF definimos os seguintes critérios de seleção dos cursos das IESP que iriam constituir o nosso universo:

\footnotetext{
${ }^{2}$ De acordo com o Processo de Bolonha e as novas designações para o Espaço Europeu do Ensino Superior, a formação graduada passou a definir-se como formação de $1^{\circ}$ Ciclo, a formação pós-graduada, a nível de mestrado, como formação de $2^{\circ}$ Ciclo, correspondendo o curso de doutorado ao $3^{\circ}$ Ciclo de formação superior.
} 
(i) Incluir cursos de todos os “Grandes Grupos - Áreas de Estudos” exceto dos “Grandes Grupos” correspondentes às designações “0 - Programa gerais” e “9 - Desconhecido ou não especificado”, por se considerar serem ambíguos e pouco provável a sua correspondência a cursos do ensino superior (ES).

(ii) Incluir todas as "áreas de estudo" pertencentes a cada um dos "grandes grupos" considerados.

(iii) Não considerar, dentro das “áreas de estudo", as “áreas de educação e formação": (a) transversais, interdisciplinares e programas não classificados; (b) correspondentes a muitos cursos (ex. 145 e 222); (c) inadequadas a cursos para do $1^{\circ}, 2^{\circ}$ e $3^{\circ}$ ciclos do ES; (d) ligados a forças militares e militarizadas.

Após a definição destes critérios, realizou-se uma pesquisa online nos sites das IESP no sentido de se identificarem os cursos de $1^{\circ}, 2^{\circ}$ e $3^{\circ}$ ciclos que correspondiam aos critérios definidos e foi consultada toda a informação disponível online relativamente a cada um dos cursos e respetivas unidades curriculares, com o objetivo de identificar cursos e/ou unidades curriculares que fizessem referência a contextos de b-learning ou e-learning ou que de algum modo fizessem referência à inclusão de uma dimensão online nos seus processos de lecionação ou avaliação. Após esse levantamento procurou-se identificar por vários meios os responsáveis mais próximos dos cursos ou unidades curriculares em causa.

Após todo este processo, pudemos identificar um total de 15 IESP (correspondendo a 77 faculdades / institutos / escolas) com oferta formativa nos diferentes ciclos de Bolonha, relativamente à qual tinham sido identificadas referências ao seu funcionamento em modalidade de b-learning ou e-learning ou relativamente aos quais tinham sido identificadas unidades curriculares que faziam referências explícitas à utilização de ambientes e serviços online nas suas atividades de ensino, aprendizagem ou avaliação.

O questionário teve um primeiro envio eletrônico para os coordenadores/diretores dos cursos em causa no período de 04 de Março de 2011 a 11 de Março de 2011. Posteriormente a 25 de Maio de 2011 procedeu-se a um segundo envio e pedido de participação.

Considerando apenas os envios diretos de questionários para os coordenadores/diretores, obtivemos 130 respostas, o que corresponde a uma taxa de retorno de 19\%. De entre os 130 respondentes, 12 manifestaram a sua disponibilidade para colaborarem posteriormente com a equipa de investigação. Note-se que um dos objetivos do questionário passava também por identificar situações que se revelassem potencialmente relevantes para a posterior realização de estudos de caso que nos permitissem conhecer com maior profundidades as práticas de avaliação digital nos contextos (casos) em estudo. 


\section{Caraterização da amostra}

De entre os 130 sujeitos que responderam ao questionário verificou-se que 64 (49,2\%) eram do sexo masculino e 66 (50,8\%), do sexo feminino. Em termos etários, constamos uma amplitude de idades compreendida entre os 27 e os 67 anos de idades, com um valor médio de 46 anos. No que concerne à experiência docente, coerentemente, verifica-se uma grande amplitude de valores, entre um valor mínimo de 2 e 41 anos de experiência docente. Em termos médios verificou-se que o grupo de respondentes possuía cerca de 19 anos de experiência profissional, localizando-se a classe modal nos 15 anos.

\begin{tabular}{|l|l|l|l|}
\hline \multicolumn{2}{|c|}{ Caracterização etária } & \multicolumn{2}{c|}{ Experiência profissional } \\
\hline Valor médio & 45,9 & Valor médio & 19 \\
\hline Valor mínimo & 27 & Valor mínimo & 2 \\
\hline Valor máximo & 67 & Valor máximo & 41 \\
\hline
\end{tabular}

Tabela 1: Caraterização etária e de experiência profissional

Obtivemos respostas de todas as universidades públicas portuguesas, excetuando a Universidade dos Açores, (17 universidades num total de 18) e de 5 Institutos Politécnicos públicos de um total de 13 (ver Tabs. 2 e 3).

\begin{tabular}{|l|l|l|}
\hline Universidade & Freq. Abs. & Freq. Rel. \\
\hline Universidade Aberta & 22 & $16,9 \%$ \\
\hline Universidade do Porto & 19 & $14,7 \%$ \\
\hline Universidade Nova de Lisboa & 17 & $13,3 \%$ \\
\hline Universidade Técnica de Lisboa & 11 & $8,4 \%$ \\
\hline Universidade de Aveiro & 9 & $6,9 \%$ \\
\hline Universidade de Évora & 9 & $6,9 \%$ \\
\hline Universidade de Lisboa & 6 & $4,6 \%$ \\
\hline Universidade de Coimbra & 4 & $3,1 \%$ \\
\hline Universidade da Beira Interior & 3 & $2,3 \%$ \\
\hline Universidade do Minho & 2 & $1,5 \%$ \\
\hline $\begin{array}{l}\text { Ins. Sup. de Ciências do Trabalho } \\
\text { e Empresariais }\end{array}$ & 2 & $1,5 \%$ \\
\hline Universidade do Algarve & 2 & $1,6 \%$ \\
\hline Universidade da Madeira & 1 & $0,8 \%$ \\
\hline Universidade dos Açores & 0 & $0 \%$ \\
\hline
\end{tabular}

Tabela 2: Participação das Universidades 


\begin{tabular}{|l|l|l|}
\hline Institutos Politécnicos & Freq. abs. & Freq. rel. \\
\hline Instituto Politécnico de Leiria & 9 & $6,9 \%$ \\
\hline Instituto Politécnico de Setúbal & 7 & $5,3 \%$ \\
\hline Instituto Politécnico do Cávado e do Ave & 4 & $3,1 \%$ \\
\hline Instituto Politécnico de Lisboa & 4 & $3,1 \%$ \\
\hline Instituto Politécnico de Tomar & 1 & $0,8 \%$ \\
\hline
\end{tabular}

Tabela 3: Participação dos Institutos Politécnicos

\section{Modalidade de ensino em que se enquadram as respostas recolhidas}

Um dos aspetos que importa ter presente na análise das respostas dos professores diz respeito ao contexto a que os mesmos se reportam relativamente à sua experiência no domínio da avaliação com recurso a tecnologias digitais. Note-se que em 56,2\% dos casos, os professores reportam-se a experiências em contextos de ensino presencial com recurso a tecnologias. Em 24,6\% dos casos, os professores reportam-se a contextos de ensino online (Elearning enquanto modalidade de ensino/formação) e 19,2\% se reporta a situações de blearning (ensino misto presencial e a distância).

\begin{tabular}{|l|c|c|}
\hline Modalidade de ensino & Freq. absoluta & Freq. relativa \\
\hline Ensino presencial & 73 & $56,2 \%$ \\
\hline Ensino online & 32 & $24,6 \%$ \\
\hline B-learning & 25 & $19,2 \%$ \\
\hline Total & 130 & $100 \%$ \\
\hline
\end{tabular}

Tabela 4: Modalidade de ensino em que se enquadram as actividades dos professores relativamente à avaliação com tecnologias

\section{Decisões sobre a avaliação}

Em coerência com o referencial de avaliação proposto, importa ter presente quem são os intervenientes no processo decisório relativamente à problemática da avaliação. Foi solicitado aos professores que indicassem, de entre uma lista de possibilidades, qual o interveniente principal em termos de decisões globais relativamente à avaliação. As respostas obtidas sistematizam-se na tabela 5 . 


\begin{tabular}{|l|c|c|}
\hline Entidade decisora global & $\begin{array}{c}\text { Freq. } \\
\text { absoluta }\end{array}$ & Freq. relativ \\
\hline Responsável da UC & 35 & 26,9 \\
\hline Equipa docente da UC & 30 & 23,1 \\
\hline Individualmente por cada docente & 24 & 18,5 \\
\hline Instituição & 19 & 14,6 \\
\hline Faculdades/Escola/Instituto & 11 & 8,5 \\
\hline Direção/Coordenação do Curso & 9 & 6,9 \\
\hline Outra & 2 & 1,5 \\
\hline Total & 130 & 100,0 \\
\hline
\end{tabular}

Tabela 5: Interveniente principal nas decisões globais sobre avaliação

Da análise da tabela 5 resulta claro que os principais intervenientes em termos de decisões globais relativamente à avaliação são os responsáveis mais diretos das unidades curriculares: responsáveis das UC, equipa docente e/ou docente individual. Estes valores afiguram-se-nos coerentes com a prática usual no ensino superior português. De uma forma algo surpreendente, apenas em 6,9\% surge a direção/coordenação do curso como interveniente principal nas decisões sobre a avaliação, o que parece indiciar um baixo nível de articulação e coordenação em termos das práticas de avaliação nas UC de um mesmo curso. Num nível intermédio, encontramos a própria instituição ou as suas unidades orgânicas de ensino (faculdades/escolas/institutos) como principais intervenientes nas decisões globais referentes à avaliação.

Foi também solicitado aos professores que indicassem os diferentes intervenientes no processo de avaliação. Os dados recolhidos apontam claramente para os professores, no seu conjunto, enquanto docentes e enquanto responsáveis de UC como principais intervenientes no processo de avaliação, como decorre da leitura da tabela 6. Na análise dos dados da tabela 6 deve ter-se presente que estamos perante respostas que podem num caso corresponder a mútuas exclusões, por exemplo, quando a intervenção do responsável da UC é importante, embora o mesmo não lecione a UC, ou a situação inversa, em que o docente tem intervenção direta e o responsável da UC não intervém. Embora conceptualmente esta situação não devesse ser possível, o conhecimento dos investigadores do projeto permitiu identificar a existência real de situação deste tipo. Registe-se o nível relativamente baixo de intervenção dos alunos no processo de avaliação, com apenas $23 \%$ dos professores a referirem que os alunos fazem auto-avaliação e 18\% a referirem a avaliação interpares. 


\begin{tabular}{|l|l|l|}
\hline Intervenientes na avaliação dos estudantes & Com envolvimento & Sem envolvimento \\
\hline A equipa docente a leccionar na UC & $52 \%$ & $48 \%$ \\
\hline O professor responsável da UC & $51 \%$ & $49 \%$ \\
\hline Cada um dos docentes a leccionar na UC & $49 \%$ & $61 \%$ \\
\hline Cada estudante (auto-avaliação) & $23 \%$ & $77 \%$ \\
\hline Todos os estudantes (avaliação inter-pares) & $18 \%$ & $82 \%$ \\
\hline Outros (indique quem): & & ------- \\
\hline
\end{tabular}

Tabela 6: Intervenientes no processo de avaliação

\section{Recursos tecnológicos utilizados}

Pretendia-se averiguar o tipo de serviços digitais utilizados no âmbito das atividades de avaliação com recurso a tecnologias digitais quer no que concerne ao seu uso enquadrado em plataformas de E-learning - learning management systems. No que se refere aos serviços integrados em plataformas, verifica-se que a submissão de documentos (texto, áudio, vídeo) assume particular relevo relativamente aos restantes serviços (79\%), levando a presumir que há uma grande incidência no uso da tecnologia como "meio" de entrega de trabalhos. Encontramos depois a utilização de sessões assíncronas - fóruns electrónicos (47\%), seguida, a alguma distância, da entrega de testes/exames electrónicos que regista 34\% de utilização. O uso de Wikis, e-portefólios e quizzes regista valores muito idênticos, mas que não ultrapassam os $24 \%$, parecendo denotar alguma falta de familiaridade com este tipo de serviços. Poderá esta falta de familiaridade ser de ordem tecnológica (o que se coaduna com alguns dos fatores indicados como condicionantes do uso de avaliação digital, como veremos), ou poderá estar relacionada com a própria natureza destes instrumentos de avaliação, bem como com blogues e diários que registaram valores respectivamente de 13 e 11\%. Sublinha-se, ainda, nestes resultados, a pouca adesão a serviços síncronos (Webconference; Chat), o que poderá relacionar-se com falta de flexibilidade destes serviços, que requerem simultaneidade temporal aos seus utilizadores, mas certamente também relacionar-se com o facto de grande parte dos professores da nossa amostra atuarem em cenários presenciais, ou em cenários $b$ learning, o que dispensará o uso de serviços tecnológicos síncronos.

\begin{tabular}{|l|l|l|}
\hline Serviços digitais integrados em plataformas & Utiliza & $\begin{array}{l}\text { Não } \\
\text { Utiliza }\end{array}$ \\
\hline Submissão de documentos (textos, áudio, vídeo, etc.) & $79 \%$ & $21 \%$ \\
\hline Sessões assíncronas - fóruns electrónicos & $47 \%$ & $53 \%$ \\
\hline
\end{tabular}




\begin{tabular}{|l|l|l|}
\hline Serviços digitais integrados em plataformas & Utiliza & $\begin{array}{l}\text { Não } \\
\text { Utiliza }\end{array}$ \\
\hline Testes/exames de correcção automática & $34 \%$ & $66 \%$ \\
\hline wikis internos ou outros sistemas similares & $24 \%$ & $76 \%$ \\
\hline e-portefólios integrados na plataforma & $22 \%$ & $78 \%$ \\
\hline $\begin{array}{l}\text { Construção de quizzes com tecnologias integradas na } \\
\text { plataforma }\end{array}$ & $21 \%$ & $79 \%$ \\
\hline Sessões síncronas através de webconference & $18 \%$ & $82 \%$ \\
\hline Sessões síncronas através de chat & $15 \%$ & $85 \%$ \\
\hline Blogues com tecnologias integradas na plataforma & $13 \%$ & $87 \%$ \\
\hline Diários com tecnologias integradas na plataforma & $11 \%$ & $89 \%$ \\
\hline Outras tecnologias ou serviços digitais & $5 \%$ & $95 \%$ \\
\hline
\end{tabular}

Tabela 7: Serviços digitais integrados em plataformas

No que respeita aos serviços digitais não integrados em plataformas, não se evidencia uma predominância muito marcada de utilização de um ou outro serviço. Os mais referidos apontam para a publicação de documentos vídeo na Web. A um nível de valores muito próximo surgem os serviços de partilha de recursos, seguidos dos sistemas de escrita colaborativa e da produção/publicação de imagens na Web. Sistemas de construção de Mapas conceptuais, Blogues, Quizzes, E-portefólios são serviços pouco utilizados. Novamente o desconhecimento tecnológico aliado à pouca familiaridade com estes instrumentos de avaliação poderão ser a razão dos valores pouco expressivos registados. Volta a constatar-se a baixa opção por serviços síncronos, já verificada anteriormente. Quer o uso de redes sociais, quer a utilização de ambientes virtuais imersivos, surgem como serviços pouco referenciados pelos inquiridos, o que pode indiciar o provável não reconhecimento das redes sociais para fins de avaliação, bem como o desconhecimento dos professores sobre os mundos imersivos.

\begin{tabular}{|l|l|l|}
\hline Serviços digitais não integrados em plataformas & Utiliza & Não utiliza \\
\hline Produção e/ou publicação de documentos vídeo na web & $28 \%$ & $72 \%$ \\
\hline Serviços de partilha de recursos & $24 \%$ & $76 \%$ \\
\hline Sistemas de escrita colaborativa & $20 \%$ & $80 \%$ \\
\hline Produção e/ou publicação de imagens na web & $19 \%$ & $81 \%$ \\
\hline Ferramentas de construção de mapas mentais/conceptuais & $17 \%$ & $83 \%$ \\
\hline Publicação em blogues & $14 \%$ & $86 \%$ \\
\hline Sistemas de construção de quizzes e outros exercícios & $13 \%$ & $87 \%$ \\
\hline
\end{tabular}




\begin{tabular}{|l|l|l|}
\hline Sistemas de geração de testes/exames & $13 \%$ & $87 \%$ \\
\hline Produção e/ou publicação de documentos áudio na web & $13 \%$ & $87 \%$ \\
\hline Redes sociais & $11 \%$ & $89 \%$ \\
\hline Sessões síncronas através de videoconferência & $11 \%$ & $89 \%$ \\
\hline Sessões assíncronas & $11 \%$ & $79 \%$ \\
\hline Sistemas específicos de construção de e-portefólios & $10 \%$ & $90 \%$ \\
\hline Sessões síncronas através de chat & $8 \%$ & $92 \%$ \\
\hline Ambientes virtuais e imersivos & $8 \%$ & $92 \%$ \\
\hline Outras tecnologias ou serviços digitais (indique quais) & $8 \%$ & $92 \%$ \\
\hline Sistemas de localização geográfica & $5 \%$ & $95 \%$ \\
\hline
\end{tabular}

Tabela 8: Serviços digitais não integrados em plataformas

\section{Frequência de avaliação dos diferentes grupos de competências}

Aos professores foi solicitado que assinalassem numa escala de 4 níveis (nunca-1; raramente-2; algumas vezes-3; muitas vezes-4) a frequência com que avaliavam um conjunto de competências consideradas essenciais nos alunos do ensino superior. Na tabela 9 representam-se os dados agregados correspondentes às respostas que assinalaram a opção “Nunca” ou "Raramente” e às respostas que assinalaram as opções “Algumas vezes” ou “Muitas vezes”. Procedeu-se também ao cálculo da média obtida com a atribuição de um valor numérico a cada uma das possibilidades de resposta.

\begin{tabular}{|c|c|c|c|}
\hline Competências: & 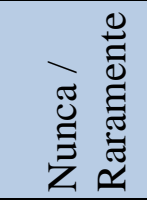 & 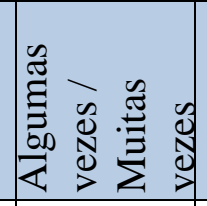 & 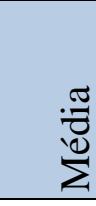 \\
\hline específicas da área científica da UC & $12 \%$ & $88 \%$ & 3,2 \\
\hline de pesquisa e análise de recursos disponíveis na web & $35 \%$ & $65 \%$ & 2,8 \\
\hline de comunicação & $42 \%$ & $58 \%$ & 2,7 \\
\hline associadas à realização de trabalho de grupo & $35 \%$ & $65 \%$ & 2,6 \\
\hline de resolução de problemas & $38 \%$ & $62 \%$ & 2,6 \\
\hline de reflexão & $42,4 \%$ & $58,6 \%$ & 2,6 \\
\hline associadas à criatividade e originalidade & $46 \%$ & $54 \%$ & 2,4 \\
\hline associadas ao uso das TIC & $58,6 \%$ & $41,4 \%$ & 2,1 \\
\hline
\end{tabular}

Tabela 9: Frequência de avaliação das diferentes competências 


\section{Fatores condicionantes do uso}

Um dos objetivos do inquérito aos professores passava por identificar as suas perceções sobre possíveis fatores condicionantes da adesão aos processos de avaliação com recursos digitais. Na tabela 10 sistematizam-se os dados recolhidos sobre esta problemática.

Quando inquiridos relativamente às razões que consideram condicionarem o uso de processo de avaliação digital, de um conjunto de potenciais fatores destacam-se os referentes à falta de conhecimentos, quer relativamente ao próprio uso das tecnologias na área científica de docência, quer no que concerne especificamente ao desconhecimento de como avaliar atividades online, com perto de 70\% dos respondentes (respetivamente 69\% e 67\%) a assinalarem estas razões. Este aspeto parece-nos de destacar por indiciar claramente a necessidade de promover a discussão e formação no domínio da utilização das TIC e da avaliação digital.

Num segundo nível de valores encontram-se razões também diretamente relacionadas com os docentes, como seja o "dispêndio de tempo acrescido por parte dos docentes” (38\%) e o “esforço adicional de aprendizagem por parte dos docentes” (35,4\%). A estas razões, e com valor similar, surge também o "receio de eventuais problemas técnicos” (aproximadamente $34,6 \%)$. Note-se que embora os dados recolhidos apontem no sentido de um reconhecimento implícito de necessidade de formação, a preocupação com o “tempo de aprendizagem” pode constituir-se como um obstáculo à eventual recetividade a iniciativas nesse sentido.

Entre as razões menos evocadas como condicionantes do uso dos processos de avaliação digital, encontra-se o “considerar que não há interesse em adotar práticas de avaliação digital” (assinalado por 18\%) e a "preferência pelos documentos em papel” (assinalado por 15\%). Estes valores reforçam a ideia da existência de uma recetividade potencial às práticas de avaliação digital.

\begin{tabular}{|l|l|l|l|l|}
\hline Fatores condicionantes... & \multicolumn{2}{l|}{ Sim } & \multicolumn{2}{l|}{ Não } \\
\hline $\begin{array}{l}\text { conhecimentos insuficientes dos docentes sobre o uso das } \\
\text { tecnologias na área científica }\end{array}$ & 89 & $69 \%$ & 41 & $32 \%$ \\
\hline $\begin{array}{l}\text { conhecimentos insuficientes sobre como avaliar atividades } \\
\text { online (exemplo: avaliar participações nos fóruns) }\end{array}$ & 87 & $67 \%$ & 43 & $33 \%$ \\
\hline dispêndio de tempo acrescido por parte dos docentes & 49 & $38 \%$ & 81 & $62 \%$ \\
\hline
\end{tabular}




\begin{tabular}{|l|l|l|l|l|l|}
\hline Fatores condicionantes... & \multicolumn{3}{l|}{ Sim } & \multicolumn{2}{l|}{ Não } \\
\hline esforço adicional de aprendizagem por parte do docente & 46 & $35 \%$ & 84 & $65 \%$ \\
\hline receio de eventuais problemas técnicos & 45 & $35 \%$ & 85 & $65 \%$ \\
\hline $\begin{array}{l}\text { receio de favorecer/prejudicar os estudantes em função da sua } \\
\text { literacia tecnológica }\end{array}$ & 28 & $22 \%$ & 102 & $79 \%$ \\
\hline $\begin{array}{l}\text { considerar que não há interesse em adotar práticas de avaliação } \\
\text { digital }\end{array}$ & 23 & $18 \%$ & 107 & $82 \%$ \\
\hline preferência pelos documentos em papel & 19 & $15 \%$ & 111 & $85 \%$ \\
\hline dispêndio de tempo acrescido por parte dos estudantes & 4 & $3 \%$ & 126 & $97 \%$ \\
\hline
\end{tabular}

Tabela 10: Fatores condicionantes do uso de processos de avaliação com recurso a tecnologias digitais

Importa referir que de entre as razões indicadas como podendo ser condicionantes do uso de processo de avaliação digital, a que foi assinalada por menor número de sujeitos foi “dispêndio de tempo acrescido por parte dos estudantes”.

Note-se que era dado aos sujeitos a possibilidade de indicarem outras razões que, no seu entender, fossem fatores condicionantes do recurso à avaliação digital, sendo que não foram registadas indicações de outras razões que não as enumeradas no questionário.

\section{Síntese das Conclusões e Considerações Finais}

Um dos aspetos que pensamos ser de destacar nos dados recolhidos é a grande amplitude de idades e um valor etário médio relativamente alto (46), o que indicia com clareza que a problemática da adesão a práticas de avaliação digital não está diretamente relacionada com a faixa etária dos intervenientes, considerando as caraterística da amostra em causa. Também no que concerne ao género, os dados não sugerem qualquer tipo de relação com a adesão a práticas de avaliação com recurso a tecnologias digitais.

Relembra-se que a leitura dos dados apresentados e a interpretação dos mesmos deve ser realizada tendo presente que mais de $56 \%$ dos professores se reportaram a situações de ensino presencial com recurso a tecnologias digitais. Este aspeto é facilmente compreensível se considerarmos que, excetuando a Universidade Aberta, todas as outras instituições de ensino superior público em Portugal são instituições de ensino presencial que apenas nos últimos anos, em alguns casos, começaram a promover iniciativas em modalidade de blearning ou online.

Os dados recolhidos relativamente aos intervenientes nas decisões referentes ao processo de avaliação apontam os professores, enquanto docentes e/ou responsáveis das unidades curriculares, como os principais intervenientes. A intervenção dos estudantes nas 
decisões referentes à avaliação são bastante reduzidas, e quando existem, são centradas em tarefas de autoavaliação. À luz do referencial proposto, estes dados refletem alguma fragilidade das práticas de avaliação no que concerne à dimensão "transparência”, nomeadamente no que concerne aos critérios de “democratização” e de “envolvimento”, que preconizam o envolvimento dos estudantes nas decisões e práticas de avaliação (PEREIRA, OLIVEIRA \& TINOCA, 2010).

A análise dos dados referentes ao tipo de recursos tecnológicos utilizados indica que os mesmos são essencialmente utilizados para submissão de documentos, o que coloca a questão se o seu uso não representará apenas uma forma “digital” de entregar "trabalhos”, em alternativa à sua entrega aos professores em suporte físico.

Quando a avaliação se faz através de learning management systems (LMS) os sistemas de testes/exames de correção automática são o terceiro tipo de serviços mais utilizados, o que também sugere alguma abordagem "tradicional” da avaliação, embora com recurso a tecnologias digitais. Quando se analisa a utilização de serviços exteriores a LMS, o recurso a sistemas de testes/exames com correção automática fica na oitava posição em termos de número de utilizadores.

É também de destacar que nos casos em que as atividades de avaliação digital se desenvolvem integradas em learning management systems, o recurso a fóruns de discussão destaca-se relativamente a outros recursos existentes. Este destaque não existe nos casos em que os professores efetuam atividades de avaliação com base em serviços da web, não integrados em LMS específicos. Neste segundo caso, serviços de “partilha de recursos” ou de “escrita colaborativa” assumem maior utilização.

Quer os serviços utilizados estejam integrados em LMS, ou não, constata-se que a comunicação síncrona tem uma utilização bastante inferior à comunicação assíncrona. Uma possível explicação para esta situação pode estar associada ao facto de um grande número dos professores atuarem em contextos presenciais ou de blearning, pelo que a existência de comunicação face-to-face reduz a relevância do recurso a processos de mediatização tecnológica deste tipo de interação. Por outro lado, a flexibilidade da comunicação assíncrona, adaptando-se à disponibilidade dos intervenientes no processo, será certamente outro dos factores que justificam o predomínio da sua utilização.

O recurso a tecnologias digitais no processo de avaliação configura, por um lado, um cenário de promoção da sua utilização e, por outro lado, um cenário de reconhecimento da presença das mesmas nos contextos em que os estudantes se enquadram. Neste sentido, o recurso às tecnologias digitais pode ser perspetivado, à luz do referencial proposto, como em 
elemento integrante da dimensão “autenticidade”, particularmente no que concerne ao critério de "similitude”, no qual se preconiza que “... a avaliação deve refletir as competências necessárias à vida real/profissional.” (PEREIRA, OLIVEIRA \& TINOCA, 2010).

No que concerne à natureza das competências avaliadas com maior frequência pelos professores, os dados permitem destacar a avaliação de competências da área específica das unidades curriculares em causa e as competências relacionadas com a pesquisa e análise de recursos disponíveis na web. Embora estas últimas competências estejam associadas ao uso das tecnologias da informação e comunicação, quando o foco da análise é frequência de avaliação de competências “associadas ao uso das TIC” o valor médio é o menor de todo o conjunto de competências consideradas no estudo. Este dado pode indiciar que embora o conjunto dos professores em causa integrem as tecnologias digitais nas suas atividades, o que pode revelar uma valorização do seu uso, não manifestam grande preocupação com a avaliação do desenvolvimento de competências neste domínio, o que pode indiciar que na verdade estas são essencialmente usadas como um meio e não como um fim em si mesmo.

A concluir, importa referir que este estudo integra-se num projeto de investigação mais amplo ainda em curso, em cujo contexto nos encontramos a realizar um conjunto de estudos de caso, visando caraterizar profundamente percepções e práticas de avaliação com recursos digitais. Os dados recolhidos nos questionários aos professores foram muito relevantes, quer na identificação de professores dispostos a colaborar com a equipa de investigação na fase seguinte do projecto, quer na identificação das áreas de questionamento mais relevantes a considerar durante os estudos de caso.

\section{Referências}

AMANTE, Lúcia. A Avaliação das Aprendizagens em Contexto Online: O e-portefólio como Instrumento Alternativo. In Paulo Dias \& António Osório (Orgs.) Aprendizagem (In)Formal na Web Social. Centro de Competência da Universidade do Minho, Braga, pp. 221-236, 2011.

BAARTMAN, Liesbeth, BASTIAENS, Theo, KIRSCHNER, Paul \& VLEUTEN, Cees. Evaluating assessment quality in competence-based education: A qualitative comparison of two frameworks. Educational Research Review, 2, pp. 114-129, 2007.

BIRENBAUM, Menucha. Assessment 2000: Towards a pluralistic approach to assessment. In M. Birenbaum \& F. J. R. C. Dochy (Eds.), Alternatives in assessment of achievement, learning processes and prior knowledge (pp. 3-29). Boston: Kluwer Academic Publishers, 1996. 
BLANCO, Ascensión (coord.) Desarrollo y Evaluación de Competencias en Educación Superior. Madrid: Narcea, S.A. de Ediciones, 2009.

DIERICK, Sabine \& DOCHY, Filip. New lines in edumetrics: new forms of assessment lead to new assessment criteria. Studies in Educational Evaluation, 27, pp. 307-329, 2001.

GOMES, Maria João. “Desafios do e-learning: do conceito às práticas”. In Leandro S. Almeida e Bento D. Silva (orgs.). Actas do VIII Congresso GalaicoPortuguês de PsicoPedagogia, Braga: CIEd / IEP / UM; pp. 66-76, 2005a.

GOMES, Maria João. E-Learning: reflexões em torno do conceito. In Paulo Dias e Varela de Freitas (orgs.). Actas da IV Conferência Internacional de Tecnologias de Informação e Comunicação na Educação - Challenges'05, Braga: Centro de Competência da Universidade do Minho, Braga, pp. 229-236, 2005b.

OCDE. Directorate for Education, Employment, Labour and Social Affairs. Definition and Selection of Competences - Theoretical and Conceptual Foundations. Strategy Paper, 2002.

PEREIRA, Alda, OLIVEIRA, Isolina \& TINOCA, Luís. A Cultura de Avaliação: que dimensões? In F. Costa, G. Miranda, J. Matos, I. Chagas \& E. Cruz (Eds.). Actas do I Encontro Internacional TIC e Educação: TICeduca 2010. Lisboa, Novembro 2010.

Recebido em: maio de 2012 Aprovado em: setembro de 2012 